\title{
KIMURA DISEASE - A RARE CASE
}

Rajeev Pastapur ${ }^{1}$, Ashfaque Ansari², R.B. Bohra ${ }^{3}$, Reena Vare ${ }^{4}$, Suma Moni Mathew ${ }^{5}$

\section{HOW TO CITE THIS ARTICLE:}

Rajeev Pastapur, Ashfaque Ansari, RB Bohra, Reena Vare, Suma Moni Mathew. "Kimura disease - a rare case". Journal of Evolution of Medical and Dental Sciences 2013; Vol. 2, Issue 45, November 11; Page: 8860-8863.

ABSTRACT: Kimura's disease is a unique chronic inflammatory angiolymphoid proliferative disorder with a poorly understood pathogenesis occasionally misdiagnosed as malignant tumour or other serious diseases. It is more prevalent in young oriental males, presenting with sub dermal lesions in the head and neck, lymphadenopathy, eosinophilia and elevated serum Immunoglobulin E. We report a case of a 40 year old female presenting with a left infra auricular swelling, based on clinical, histopathological and laboratory findings, a diagnosis of Kimura's disease was made. The patient responded well to surgery and followed by post operative long term low dose steroids and antihistaminics during the last 18 months of follow up period.

KEYWORDS: Kimura disease, eosinophilia.

INTRODUCTION: Kimura Disease (KD) is a rare chronic inflammatory disorder, which was first described in 1937 by Kim and Szeto in the Chinese literature as "eosinophilic hyperplastic lymphogranuloma" and has been known most often as Kimura's disease since its description by Kimura et al. in the Japanese literature in $1948^{1}$. The most common clinical feature of this disease is a soft-tissue mass in the head and neck area, with major salivary glands and lymph nodes frequently involved. It affects young men between 20 to 40 years of age with a male to female 3:1 ratio ${ }^{2}$. The diagnosis of $\mathrm{KD}$ is often difficult, and the biopsy or excision of the involved mass for a pathologic study is necessary. Here we report a rare case of a 40 year old female with left infra-auricular swelling. The clinical presentation, pathological confirmation and treatment options for this relatively rare tumour are discussed.

CASE REPORT: A 40 year old female presented with a painless, progressive, itchy, nodular and irregular swelling below the left ear since 15 years (fig 1). There was no history of pain, fever, night sweats, weight loss, hypertension, diabetes mellitus or family history of tuberculosis. She had undergone 2 time surgical excision 12 and 5 years back elsewhere, details of which and histopathological reports were not available. The swelling recurred after 2 years of second time excision and the patient was not on any medical treatment after the excision. The patient was referred to us 2 years back for further treatment.

On examination; a swelling in the left infra auricular region extending to the retro-auricular region, of size $6 \times 3 \mathrm{~cm}$ was visible. On palpation, it was firm, non tender, non fluctuant; the skin overlying was thickened, not free from the underlying mass with a previous surgical scar and excised left ear lobule (fig 1 ). There were multiple non tender, non ballotable swellings of $1 \times 1 \mathrm{~cm}$ size in left submandibular region (lymph nodes). Rest of her vitals and general examination was normal.

On investigation; Ultrasonography showed an echo complex mass lesion in the left parotid region and multiple dilated vascular channels within it and few enlarged submandibular lymph nodes. We did computed tomography to rule out deeper structure involvement. Computed 
tomography showed a moderately enhancing lesion $6.2 \times 3 \mathrm{~cm}$ below the left pinna extending to the parotid region (parotid gland is spared) involving the skin \& the subcutaneous tissue with submandibular lymph nodes (fig 2). Rest of haematological, urine \& serum biochemistry tests were normal except for eosinophilia 22\% (normal 1-3\%) and Absolute eosinophil count: 2200/cumm(40440/cumm).

We subjected the patient for wide excision of the mass with primary closure. The specimen was sent for the histopathological report. The histopathological report showed thin vascular proliferation with atypical endothelial lining, lymphoid tissue proliferation, dense lymphocytic infiltration with abundant eosinophils typical of Kimura's disease (fig 3).

In view of its recurrence and histopathological report showed kimura's disease, we started the patient on low dose oral steroid (prednisolone 20mg OD) and antihistamine (cetrizine 10mg OD) with regular monitoring of blood pressure \& blood glucose levels. She is on follow-up since 18 months and has been symptom-free and did not demonstrate any sign of recurrence.
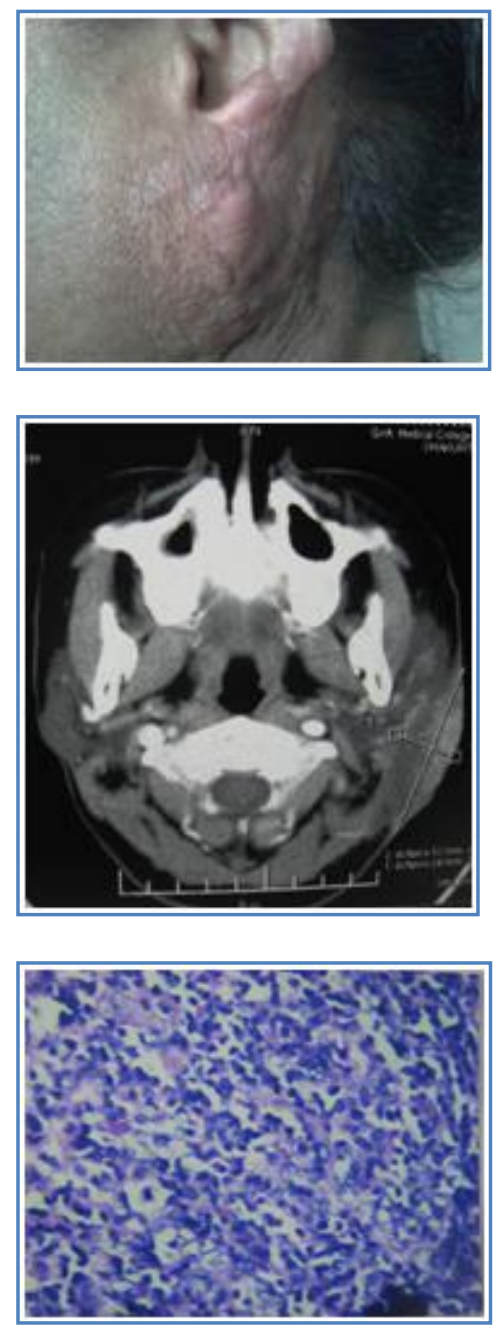

Fig. 1: clinical picture
Fig. 2: Computed tomography- moderately enhancing lesion $6.2 \times 3 \mathrm{~cm}$ below the left pinna extending to the parotid region involving the skin \& the subcutaneous tissue with submandibular lymph nodes.
Fig. 3: HPE-showed thin vascular proliferation with atypical endothelial lining, lymphoid tissue proliferation, dense lymphocytic infiltration with abundant eosinophils.

DISCUSSION: Kimura's Disease (KD) is a rare, chronic inflammatory disorder affecting the tissue of lymph node ${ }^{1}$.The aetiology of KD is still unknown; a number of theories have been suggested for the 


\section{CASE REPORT}

origin of $\mathrm{KD}$, including impairment or interference with immune regulation, atopic reaction to a persistent antigenic stimulus by arthropod bites and virus ${ }^{3}$. It affects young men, with a majority of patients being between the ages of their 2 nd and 3rd decades, in a 3:1(male: female) ratio ${ }^{2}$ KD presents as a slow growing, deep, subcutaneous mass in the head and neck region and is frequently associated with regional lymphadenopathy or salivary gland involvement with eosinophilia and elevated serum IgE2 2 . Less frequently, the eyelids, orbit, lacrimal glands, epiglottis, larynx, tympanic membrane, median nerve and spermatic cord, elbows, heart, axillary or popliteal region, and chest wall may be involved 4 .

The diagnosis of KD is not easy, and clinically differential diagnosis includes inflammatory and neoplastic conditions, tuberculosis, angiolymphoid hyperplasia with eosinophilia (AHLE), lymphocytoma, Kaposi's sarcoma, epitheloid hemangioma, pyogenic granuloma and other infectious lymph node enlargements for example, toxoplasmosis. The disease is characterized with hyperplasia of the lymphoid tissue with well-developed lymphoid follicles, marked lymphocyte (eosinophil) infiltration, proliferation of thin-walled capillary venules, and varying degrees of fibrosis ${ }^{1}$, this makes it differentiate from other conditions.

Ultrasound, computed tomography (CT) and magnetic resonance imaging (MRI) might be diagnostic and can help staging the extent and progression of the disease as well as the lymph node involvement. The diagnostic challenge of KD is generally solved by histological study of excised lesion ${ }^{3}$.

Therapies for KD include surgical excision, steroid and radiation, but the treatment of choice is still controversial. The effect of systemically administered steroids (prednisolone) show good effects on disease progression; however, withdrawal can often result in tumour relapse ${ }^{5}$. Radiation has been utilized for steroid resistant lesions 6 . Besides, the treatment of KD with cyclosporine has also been reported ${ }^{8}$. Surgical excision may be considered first especially for the localized lesion, even if recurrence is possible ${ }^{1,7}$, however, radical surgery should be avoided since no malignant transformation has been reported in the literature?

CONCLUSION: The relevance of this case is due to the rarity of the disease which mimics neoplastic conditions. In KD recurrence is common and requires multimodality treatment and long term follow up. This disease should be considered as a differential diagnosis in patients presenting with head \& neck mass and lymphadenopathy and investigated accordingly. Knowledge of Kimura's disease put the physicians in a better position to diagnose and treat the disease.

\section{REFERENCES:}

1. Kimura T, Yoshimura S, Ishikawa E. On the unusual granulation combined with hyperplastic changes of lymphatic tissues. Trans Soc Pathol Jpn. 1948;37:179-80.

2. Hui PK, Chan JK, Ng CS, Kung IT, Gwi E (1989) Lymphadenopathy of Kimura's disease. Am J Surg Pathol 13:177-186.

3. Tseng CF, Lin HC, Huang SC, Su CY: Kimura's disease presenting as bilateral parotid masses. Eur Arch Otorhinolaryngol 2005, 262:8-10.

4. Sun QF, Xu DZ, Pan SH, Ding JG, Xue ZQ, Miao CS, Cao GJ, Jin DJ: Kimura disease: review of the literature. Intern Med J 2008, 38:668-672. 
5. Hui PK. Chan YW (1990) Kimura's disease: treatment with steroids. Histopathology 17:286287.

6. Kim GE, Kim WC, Yang WI, Kim SK, Oh WY, Suh HS, Hahn JS, Park CS (1997) Radiation treatment in patients with recurrent Kimura's disease. Int J Radiat Oncol Biol Phys 38:607612.

7. Armstrong WB, Allison G, Pena F, Kim JK (1998) Kimura's disease: two case reports and a literature review. Ann Otol Rhinol Laryngol 107:1066-1071.

8. Kaneko K, Aoki M, Hattori S, Sato M, Kawana S (1999) Successful treatment of Kimura's disease with cyclosporine. J Am Acad Dermatol 41:893-894.

\section{AUTHORS:}

1. Rajeev Pastapur

2. Ashfaque Ansari

3. R.B. Bohra

4. Reena Vare

5. Suma Moni Mathew

\section{PARTICULARS OF CONTRIBUTORS:}

1. Assistant Professor, Department of ENT, MGM Medical College \& Hospital, Aurangabad.

2. Assistant Professor, Department of ENT, MGM Medical College \& Hospital, Aurangabad.

3. Professor \& HOD, Department of ENT, MGM Medical College \& Hospital, Aurangabad.

4. Associate Professor, Department of ENT, MGM Medical College \& Hospital, Aurangabad.
5. Resident, Department of ENT, MGM Medical College \& Hospital, Aurangabad.

\section{NAME ADDRESS EMAIL ID OF THE CORRESPONDING AUTHOR:}

Dr. Rajeev Pastapur, Assistant Professor, Department of ENT and Head \& Neck Surgery, MGM Medical College \& Hospital, N-6, CIDCO, Aurangabad, Maharashtra - 431003. Email - rajeev.pastapur@rediffmail.com

Date of Submission: 22/10/2013. Date of Peer Review: 23/10/2013. Date of Acceptance: 06/11/2013. Date of Publishing: 07/11/2013 